\title{
A Review on Key Issues and Challenges in Devices Level MEMS Testing
}

\author{
Muhammad Shoaib, Nor Hisham Hamid, Aamir Farooq Malik, \\ Noohul Basheer Zain Ali, and Mohammad Tariq Jan \\ Department of Electrical \& Electronic Engineering, Universiti Teknologi PETRONAS, 32610 Bandar Seri Iskandar, \\ Perak Darul Ridzuan, Malaysia
}

Correspondence should be addressed to Muhammad Shoaib; shoaib-shafi@hotmail.com

Received 5 November 2015; Revised 21 January 2016; Accepted 24 January 2016

Academic Editor: Eugenio Martinelli

Copyright (C) 2016 Muhammad Shoaib et al. This is an open access article distributed under the Creative Commons Attribution License, which permits unrestricted use, distribution, and reproduction in any medium, provided the original work is properly cited.

\begin{abstract}
The present review provides information relevant to issues and challenges in MEMS testing techniques that are implemented to analyze the microelectromechanical systems (MEMS) behavior for specific application and operating conditions. MEMS devices are more complex and extremely diverse due to the immersion of multidomains. Their failure modes are distinctive under different circumstances. Therefore, testing of these systems at device level as well as at mass production level, that is, parallel testing, is becoming very challenging as compared to the IC test, because MEMS respond to electrical, physical, chemical, and optical stimuli. Currently, test systems developed for MEMS devices have to be customized due to their nondeterministic behavior and complexity. The accurate measurement of test systems for MEMS is difficult to quantify in the production phase. The complexity of the device to be tested required maturity in the test technique which increases the cost of test development; this practice is directly imposed on the device cost. This factor causes a delay in time-to-market.
\end{abstract}

\section{Introduction}

Since the mid-1970, MEMS (microelectromechanical systems) have emerged as an innovative technology by creating new opportunities in physical [1], chemical [2], and biological [3] sensors and actuator applications. Although MEMS technology emerges from IC fabrication techniques, test methods [4] of both technologies significantly differ from each other. This is because MEMS devices respond to both electrical and nonelectrical (physical, chemical, biological, and optical) stimuli.

MEMS devices are tested at different stages during manufacturing processes. This testing is essential to verify the performance metrics of the device, parametrically and functionally. After wafer level fabrication, MEMS are tested by measuring all $\mathrm{AC}$ and DC parameters at wafer level $[5,6]$ using an ATE (Automatic Test Equipment) [7]. This test phase sorts out the wafer for good and bad die by exploiting design for testability circuitries within chip, for instance, self-test mechanisms and scan chains, similarly to common integrated circuits. This is followed by dicing and wire bonding to test the electrical performance; at last, good devices are packaged. In the final stage, these packaged devices are retested parametrically to confirm their overall functionalities. Functional testing and calibration are essential for every MEMS sensor before proper utilization. Therefore, some intrinsic constants or values that belong to the device performance are captured during calibration as reported in [8-10]. Functionality of the device is measured by applying known physical and electrical stimuli and comparing output responses of the device. If the measured output values are different from the estimated one, the device is considered as failed; otherwise, it is accepted as a good device. Comprehensive details of infrastructures about Automatic Test Stations and methods for MEMS testing are reported in $[11,12]$. As an example, the fabrication and testing steps in detail for mass production of MEMS pressure sensor are presented in Figure 1.

In MEMS manufacturing process, testing has an important role in verifying performance and reliability of the device; however, this testing process consumes a huge cost 


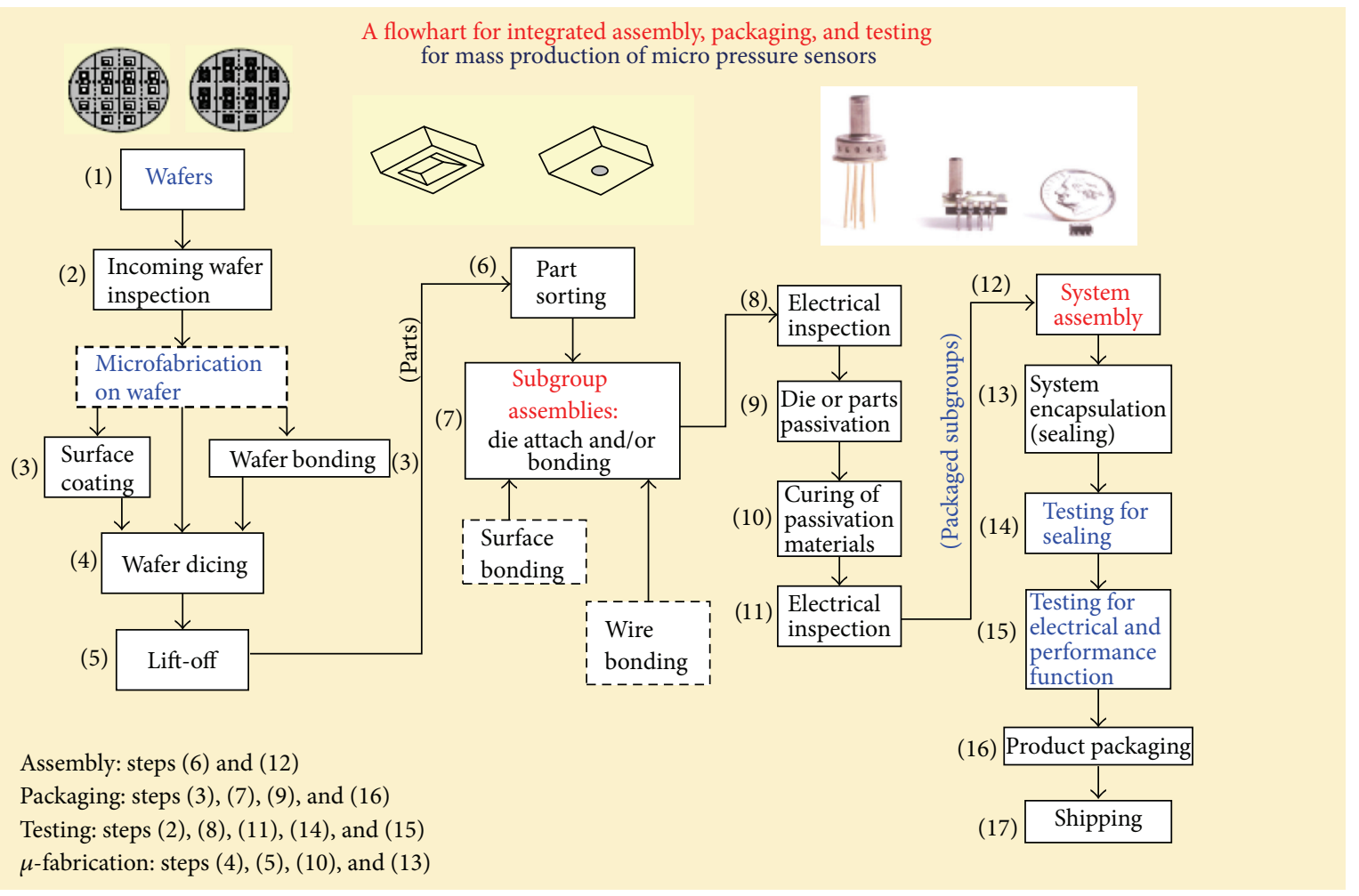

FIGURE 1: Steps for mass production of MEMS pressure sensor [13].

[14]. A plethora of work is reported on the cost of MEMS testing process. Masi and Cortese $[15,16]$ reported that 25$35 \%$ cost is consumed in overall testing process. According to Texas Instruments [17], in case of testing digital micromirror device, the cost of final test (packaged device testing) is $14 \%$ whereas the cost of wafer level test is $8 \%$. MEPTEC (Microelectronics Packaging and Test Engineering Council) $[18,19]$ reported that the cost of MEMS testing is $20-45 \%$ of the total device manufacturing cost. On the other hand, in MEMS test standard report of MIG (MEMS Industry Group) [20], testing cost at manufacturing level can accede up to $50 \%$ due to device complexity and maturity. Henttonen [21] reported more than $60 \%$ testing cost of the device; the reason of this huge cost is that testing systems are mostly associated with automotive sensor testing which can be costly to be adopted as testing systems for ordinary consumer MEMS devices listed in [22].

Therefore, it is of utmost importance to find a suitable alternate to reduce the huge cost of test. A work has been reported on the reduction of testing cost. One way of cost reduction technique is to increase the test throughput by testing multiple DUTs (device under test) in parallel $[23,24]$. Substantial research efforts have been practiced to reduce test time and cost by examining various aspects of test [25]. These techniques of parallel testing have been widely used in VLSI test areas [26]. However, these testing techniques are not fully applicable to MEMS because MEMS devices operate under working principle of different domains (electrostatic, electromagnetic, electrothermal, piezoelectric, etc.).
The scope of this review is to highlight the issues of MEMS testing at device and batch levels. The current batch level technique is the parallel testing in which electrical and nonelectrical test stimuli are used for the response of multiple DUTs. Enhancing the parallelism of test system has been tried to reduce the cost. However, these parallel test techniques have issues and limitations that are discussed in the following section. Section 2 differentiates the ICs and MEMS test techniques while Section 3 highlights the failure mechanism and defects in different categories of MEMS devices. Section 4 presents customized testing techniques and also describes the destructive and nondestructive test techniques. Section 5 discusses the issues at device level testing while Section 6 reports on issues in parallel testing techniques in detail. Finally, some conclusions are extracted at the end.

\section{Difference between ICs and MEMS Testing}

MEMS have to face many testing challenges [27] due to their multiphysics behavior. Similar to analog electronic systems, the mechanical components of MEMS have nonlinear nature. Therefore, analog and mixed signal tests [28] including verification and calibration are essential for MEMS. The test problem for MEMS is exacerbated due to their inherent diverse properties. For example, the output of a MEMS based device is electrical in nature; however, these signals come from mechanical actuations under different domains. Thus, the use of electrical signals for test was found helpful to 
TABLE 1: Comparison between ICs systems and MEMS.

\begin{tabular}{|c|c|c|c|}
\hline Testing approach & Integrated digital devices & Analog mixed signal devices & Microelectromechanical systems \\
\hline Fault model & $\begin{array}{l}\text { Assertion, gate delay, line delay, } \\
\text { redundant, path delay, behavioral, } \\
\text { branch, bus, cross-point, } \\
\text { stuck-open, stuck-at, stuck-on, } \\
\text { bridging, and so forth. }\end{array}$ & $\begin{array}{l}\text { Hierarchical, behavioral, macro } \\
\text { model, transistor, physical, } \\
\text { catastrophic, and parametric faults } \\
\text { and so forth. }\end{array}$ & $\begin{array}{c}\text { Behavioral, shorts and opens in } \\
\text { electrothermal and electromagnetic, } \\
\text { structural defect level, parametric, } \\
\text { functional, fatigue, and reliability } \\
\text { model. }\end{array}$ \\
\hline Test technique & $\begin{array}{l}\text { VHDL, HSPICE, fault dictionary, } \\
\text { probabilistic, signature analysis } \\
\text { method, LFSR (linear feedback shift } \\
\text { register), BIST (built in self-test), } \\
\text { and so forth. }\end{array}$ & $\begin{array}{l}\text { Pole-Zero Analysis, artificial neural } \\
\text { network, HSPICE, SABER, } \\
\text { VHDL-AMS, ATPG, diagnosis of } \\
\text { soft faults based on fractional } \\
\text { correlation, BIST (built in self-test), } \\
\text { and so forth. }\end{array}$ & $\begin{array}{l}\text { Neural network, VHDL-AMS, } \\
\text { device-level (FEM) and HDLs and } \\
\text { transposition of techniques } \\
\text { developed for microelectronics, } \\
\text { BIST (built in self-test). }\end{array}$ \\
\hline
\end{tabular}

an extent for controllability and observability of mechanical components. Field of MEMS is relatively not as advanced as ICs. MEMS testing and fault modeling [29] are a new area as compared to MEMS manufacturing and designing. Even though MEMS devices have been introduced since 1970, testing MEMS remained a big challenge. Testing MEMS at the early stage can help in production, fabrication, and packaging flow. The testing tools required to diagnose the origins of MEMS failures are essential to upgrade and design.

Causes of failures [30] are as distinctive as the MEMS devices. In ICs manufacturing, significant efforts are being done in testing and handling to appropriately characterize and judge the device performance in comparison with the device specifications. The main differences in testing MEMS and ICs are the environmental circumstances. For several cases, integrated circuits are being analyzed in a variety of environments under different conditions of temperature and moisture. Relatively analogous testing and handling measures [31] are being performed during manufacturing process; however, essentially, the device is operated within different environmental conditions. Any change in the test environment can considerably affect the sensitivity and functionality of the device. The additional complication regarding mechanical motion demands extra heed during testing and handling. Auspiciously, in case of MEMS analysis, there is a plus point of utilizing testing techniques [32] leveraged from IC industries. Although the variety of devices are growing because of different applications, therefore, multidisciplinary knowledge is deemed essential to properly identify the causes of failures. Table 1 briefly summarizes the difference of fault modeling and testing techniques of ICs and MEMS [33].

\section{A Comprehensive Study on Failure of MEMS Devices}

MEMS devices have features of motion unlike ICs; therefore, special techniques and tools are required for measuring mechanical response on micro- and nanoscale. The device's behavior was analyzed in detail using these tools which helped in providing feedback to improve the design. A number of MEMS devices are used in a range of applications across the world. In the past, it was considered that MEMS devices belonged to ICs family and might have the same failure issues like ICs. Conversely, MEMS devices have different failure mechanism due to complex mechanical geometry and unique material and these have different biasing techniques. The failure mechanisms due to complexity of these devices are categorized in the following four groups.

Group 1 includes stationary MEMS devices without moving parts, such as chemical sensor, microphones, and DNA sequencers. The major source of failure in this group is the particle contamination. The contaminated particles, which are small in size and inherently nonelectrical, adversely affect the device performance. The particle contaminations are insulator in nature and these are unable to bridge the device structure electrically and contaminants become difficult to detect as short circuits.

Group 2 contains MEMS devices that have moving structure without rubbing surfaces, such as comb drives accelerometers and gyroscopes, whose components like hinges and microcantilever yoke regions suffered from fatigue failure. The fatigue (structural failure) is studied in this group; electrostatically actuated comb fingers with a perforated proof mass and a microcantilever with a notch are the main constituents of this group. The increase in stress levels at the notch initializes cracks on the surface of the microcantilever that reduces device life and eventually causes the failure of the device by fracture.

Group 3 consists of MEMS devices that have moving structure with impact surfaces, such as relays, thermal actuators, and valves. These devices are easily influenced by debris created on the surfaces, fracture constituents, cracks [34], and so forth. Fracture generated due to impact forces on the opposite structure causes failure in the device.

Group 4 surrounds MEMS devices that have moving parts, rubbing, and impacting surfaces, for instance, micromirror, optical shutter, and geared devices. Friction is created due to rough surfaces of moving components that create wear in material or debris initiating several failures, such as (1) stiction of rubbing or contacting surfaces, (2) wear created by particles that can change the motion tolerance, and (3) particle contamination.

3.1. Reliability Test of MEMS Devices for Failure Analysis. The functionality of MEMS devices depends upon its material of structure, design, and actuating parts. Therefore, electronic industry also prefers the reliability test of MEMS based products. Reliability test of MEMS devices is a major challenge in 
manufacturing at mass production level. In this test, failure analysis of DUT is performed under certain conditions of device application for a specific time period. The origins of MEMS reliability failures highly depend upon product and application environment. Reliability test also requires a costeffective technique for characteristic failure analysis in order to understand the mechanical and electrical properties of DUT.

It is perceptible that all kinds of MEMS devices have failure mechanisms due to particle contamination and stiction, and so forth. It is, therefore, more important to understand the origins of failure before finding the remedies of the specific failure. MEMS sensors and actuators have different and distinctive failure mechanisms by their classifications and nature. In ICs, testing only electrical parameters is done to find the fault, while in MEMS testing both the electrical and mechanical parameters is to be done to deal with the failure. MEMS causes of failures during reliability test are summarized in Table 2.

3.2. Failures of MEMS Devices. MEMS structures consist of flexible or rigid membranes or beams such as cantilever and bridges, and some contain perforation on its surface. These devices also contain insulated or conductive flat layers, gears, cavities, and hinges integrated with an electronic readout circuit. On the other hand, more than one device is being integrated in a single chip. Single axis moving MEMS structures have been upgraded to multiaxis movements. MEMS are getting more multifaceted design features to fit for more applications. The failure analysis helps to understand the basic reasons of faulty behavior of device during testing process from wafer level to the final device packaging. Failure mechanism due to defective interconnects and low compatibility results in poor performance of the device. Table 3 indicates the foremost mechanical failures of MEMS devices. Generally, MEMS failures are not only related to only mechanical parts of the device; however, electrical failures cannot be ignored. These are originated due to contact failure, electromigration, and dielectric degradation. Table 4 shows common electrical failures of MEMS devices.

MEMS devices due to multiphysics behavior are the hardest to test. Recently, the devices are being tested on the base of functional specifications. Variations in manufacturing process of device may alter its specs, which is the disadvantageous scenario in MEMS testing, as a number of errors can be induced due to process fluctuations. Moreover, the specifications of the device are multifarious and its measurements at several testing stages may increase the test time. Therefore, quite different test techniques are required to measure the performance parameters of various devices, which forces the manufacturer to procure different test equipment for different products. Fast transient test methodologies are required to check the DUT specifications. In multistructured complex devices, specifications are disturbed mostly due to drifts in the fabrication process and defects. For the devices that were designed near the specification limits, the violations in the specifications occurred due to normal process variations. Drifts in processes were identified at initial stage in the production phase by the process monitoring systems. Defects become the reasons of catastrophic failures that were detected by tests of parametric and functional failure analysis.

\section{Development of Different Testing Techniques for MEMS Devices}

The development of cost-effective testing techniques is the major challenge for MEMS. A number of techniques and methodology have been reported in literature. Table 5 shows the list of destructive and nondestructive testing techniques that are being implemented for MEMS measurements electrically and mechanically [72]. Jeffrey et al. [73] reported an online monitoring technique which is based on bias superposition for MEMS integrated sensors. They injected the test stimuli into biased conductance sensor and analyzed the structural integrity of the device and interface on the base of signal injection and signal extraction. Islam [74] reported optical techniques to test MEMS structures at wafer level. They utilized microscopic interferometry and computer microvision to perform MEMS measurements for analyzing static and dynamic properties. Biswas et al. [75] developed statistical based $\varepsilon$-SVM model for testing MEMS accelerometer to eliminate redundancy. Their work disclosed that, with the help of specification based tests, the redundancy in test can be statistically identified with minor error. When hot and cold tests are performed for the accelerometer, they observed the defect escape of $0.2 \%$ and yield loss of 0.1. Dumas et al. [76] developed online testing technique for sensors using superposition of the test stimuli on the specifications. They utilized the signal processing technique to reduce the fluctuations of test output by encoding the test stimulus through pseudorandom sequence. They also studied the overall test time and level of perturbation rejection.

The dynamic Electrostatic Force Microscopy is used in [77] to characterize the beam resonators. The resonator was actuated by placing probe cantilever above the beam. Then, modulated signal was applied to the probe cantilever. The resonance frequency response of the test beams was analyzed by studying coupled electrostatic interaction between the conductive beams. Izadian and Famouri [78] developed fault diagnostic system for MEMS using multiple model adaptive estimation technique. They used Kalman filters to model and diagnose the fault in MEMS in real time application. Lateral comb MEMS resonators are fabricated to validate the fault diagnosis unit in multiple model adaptive estimation technique. They also developed another fault diagnosis technique [79] for MEMS resonator by combining least square forgetting-factor method and multiple model adaptive estimation method. This technique identified the parameters of slowly time-varying systems. Another work developed by Izadian [80] is the self-tuning-based parameter estimation technique for fault diagnosis of MEMS. He used this technique to recognize the parameters of system and generation of residual signals. Repchankova [81] developed an antistiction and self-recovery mechanism in order to recover the functioning of RF-MEMS switches in case of malfunctioning due to stiction. An effective heat-based mechanism was designed in order to release the stuck component. Reppa [82] developed a fault detection and diagnosis (FDD) technique 
TABLE 2: Summary of failures, their causes, and procurement for various MEMS devices.

\begin{tabular}{|c|c|c|}
\hline Group & Causes of failures & Reliability test \\
\hline \multicolumn{3}{|l|}{ Group 1} \\
\hline $\begin{array}{l}\text { Chemical sensor } \\
\text { nozzles } \\
\text { microfluidic } \\
\text { DNA sequencers }\end{array}$ & Dielectric breakdown & $\begin{array}{l}\text { The reliability test of flagellar microfluidic motors was performed } \\
\text { in environmental conditions. Probabilistic mathematical model } \\
\text { was used to analyze the rotational behavior. The decay time of } 55 \mathrm{~h} \\
\text { was predicted for the bacterial motor [35]. }\end{array}$ \\
\hline \multicolumn{3}{|c|}{ Group 1 or Group 2} \\
\hline Accelerometers & $\begin{array}{l}\text { Fracture, fatigue, mechanical } \\
\text { wear, charging, and change in } \\
\text { friction }\end{array}$ & $\begin{array}{l}\text { (1) Accelerated life time of devices was tested experimentally for } \\
1000 \text { hours at about } 145^{\circ} \mathrm{C} \text { to } 200^{\circ} \mathrm{C}[36] \text {. } \\
\text { (2) Tytron } 250 \text { was used to test fatigue. The experiment showed } \\
\text { fatigue life between } 7.78 \times 10^{4} \text { and } 1.48 \times 10^{7} \text { cycles when the } \\
\text { stresses increased from } 2.05 \text { to } 2.83 \mathrm{GPa} \text { [37]. } \\
\text { (3) Sandia National Laboratories developed the SHiMMeR (Sandia } \\
\text { High Volume Measurement of Micro Machine Reliability) that can } \\
\text { simultaneously control and test up to } 256 \text { MEMS parts [38]. } \\
\text { (4) Fatigue and creep were observed by using X-rays diffraction. } \\
\text { Wear was analyzed through DLC coating (Diamond Like Carbon), } \\
\text { stiction was observed by using MIL-STD-883F (Military Test } \\
\text { Standard Device) and SAM (Scanning Acoustic Microscope) was } \\
\text { used for contamination [39]. }\end{array}$ \\
\hline
\end{tabular}

Group 2

Pressure Sensors

Vibrations, shock Fatigue, fracture, and change in friction

Gyroscopes

Vibrations, shock, and charging

Group 3

Thermal actuators

Vibration, shock, and mechanical wear

Fatigue, fracture, mechanical wear, shock, vibrations, and charging

Micro relays

Group 4

Electrostatic

actuators

Charge in friction, fatigue,

fracture, mechanical wear, shock, and vibrations

Optical degradation, fatigue,

Mirror devices

fracture, mechanical wear, shock, and vibrations

Charge in friction, fatigue,

Gear devices

fracture, mechanical wear, shock,
The fatigue was detected in the fabricated sensors operating below the stress level; it is observed that fatigue can occur at equal stress and fracture levels [40].

(1) The reliability assessment of a three-axis gyroscope was performed under several shock loading conditions [41].

(2) The temperature degradation and variations in signal to noise ratio were also reported [42].

(1) Weibull statistics was used to analyze the fracture tests on the beam by applying different loads.

(2) Experimental technique was proposed for micro switches to observe malfunctioning due to charging and creep [43, 44].

(3) The effects of pull-in voltages were observed during bending and torsional modes of beams. Mechanical wear and fatigue tests were performed to predict the life time [45].

Effects of stiction and welding failure were performed at $10^{9}$ on/off switching cycles [46, 47]. and vibrations

for MEMS. Parametric faults can be captured, isolated, and identified with the help of this technique. This technique depends on estimation of parameters arrayed in a set membership identification framework. Zheng et al. [83] developed a characterization technique of computer microvision for microresonator. The method of video imaging is used for this technique to measure the in-plane motion of MEMS device. The blur image synthesis technique is used to obtain the magnitude of displacement.
Stochastic method was used to analyze the pull-in and pull-out voltages for prediction of device life time $[48,49]$.

Texas Instruments (TI) developed the optical inspection tool for DMD devices that examines each pixel of the DMD array [50].

Sliding surfaces were analyzed through simulations to prevent adhesion and wear [51].

\section{Issues in Device Level Testing}

MEMS devices are categorized in six different classes. The classification is based on their operating mechanism and applications are discussed in this section.

MEMS sensors $[84,85]$ are designed and fabricated for sensing multiple environmental changes. The sensors are capable of sensing behavior of fluids, force, inertia, gas, and so forth. Testing this category of devices has many challenges 
TABLE 3: MEMS mechanical failures.

\begin{tabular}{|c|c|c|c|c|c|}
\hline \multicolumn{6}{|c|}{ Mechanical fracture } \\
\hline Failure & Shock & Overload & Fatigue & Corrosion & \\
\hline Causes & $\begin{array}{l}\text { Mechanical } \\
\text { interference } \\
\text { disorder, } \\
\text { excessive } \\
\text { loading, and } \\
\text { drops }\end{array}$ & Excessive stress & $\begin{array}{c}\text { Structural } \\
\text { damage due to } \\
\text { cyclic loading }\end{array}$ & $\begin{array}{l}\text { Oxidation, } \\
\text { chemical } \\
\text { reaction }\end{array}$ & \\
\hline \multicolumn{6}{|c|}{ Stiction } \\
\hline Failure & Capillary forces & $\begin{array}{l}\text { Vander Waals } \\
\text { forces }\end{array}$ & Residual stress & $\begin{array}{l}\text { Chemical } \\
\text { bonding }\end{array}$ & $\begin{array}{c}\text { Electrostatic } \\
\text { charging }\end{array}$ \\
\hline Causes & $\begin{array}{l}\text { Monolayer of } \\
\text { moisture or } \\
\text { lubricants on } \\
\text { the surfaces } \\
\text { prompting } \\
\text { capillary force }\end{array}$ & $\begin{array}{l}\text { Interaction of } \\
\text { atoms or } \\
\text { molecules at the } \\
\text { surface of close } \\
\text { contact }\end{array}$ & $\begin{array}{l}\text { Bending and } \\
\text { deformation of } \\
\text { structure during } \\
\text { the release } \\
\text { process }\end{array}$ & $\begin{array}{c}\text { Chemical bond } \\
\text { between contact } \\
\text { surfaces }\end{array}$ & $\begin{array}{c}\text { Potential } \\
\text { difference at two } \\
\text { closed surfaces }\end{array}$ \\
\hline \multicolumn{6}{|c|}{ Wear } \\
\hline Failure & Surface fatigue & Corrosion & Abrasion & Adhesion & \\
\hline Causes & $\begin{array}{l}\text { Cyclic loading } \\
\text { instead of } \\
\text { smooth surfaces }\end{array}$ & $\begin{array}{l}\text { Chemical } \\
\text { interaction } \\
\text { between two } \\
\text { surfaces }\end{array}$ & $\begin{array}{l}\text { Material loss } \\
\text { due to sliding of } \\
\text { different } \\
\text { surfaces }\end{array}$ & $\begin{array}{c}\text { Pull-in } \\
\text { interaction } \\
\text { between two } \\
\text { surfaces during } \\
\text { sliding due to } \\
\text { surface forces }\end{array}$ & \\
\hline \multicolumn{6}{|c|}{ Creep and fatigue } \\
\hline Failure & Thermal stress & Intrinsic stress & Applied stress & & \\
\hline Causes & Overheating & Residual stress & Applied stress & & \\
\hline
\end{tabular}

TABLE 4: MEMS electrical failures.

\begin{tabular}{lcccc}
\hline & & Electric short and open circuit \\
\hline $\begin{array}{l}\text { Failure } \\
\text { Causes }\end{array}$ & Oxidation & Electromigration & ESD, high electric field & Dielectric material degradation \\
Environmental & Mismatch load & Excessive load & Capacitive discharges \\
\hline Failure & Usage environment & Intrinsic (crystal growth) & Manufacturing-induced \\
Causes & Low and high temperature and humidity & Environmental & Rough handling in industry \\
\hline
\end{tabular}

due to complex sensing functionality and a variety of designs. The test mechanism developed for theses sensors also has issues of fault detection as reported in [86-88], because each device required individual test bench to analyze the sensing environment. As these tools and testing techniques have been leveraged from the IC technology, therefore, these were helpful in resolving various fault mechanisms to an extent. The major dilemma was to discover the faulty origins in multiple devices that were put together on single test bench for mass production. Recently existing tools [89] have limitations to test specific MEMS devices electrically and mechanically. The emerging challenge is to analyze and identify unique source of failure during assessment of multiple die on single test stage.

In the development of a test bench for gas sensors, the main obstacle was the chamber designing for chemical environment for the device sensibility. Mechanical sensors
[90, 91] that are designed to sense physical changes like motion and pressure are relatively easy to test or characterize, while chemical sensors have issues of selectivity in case of sensing targeted gases. Carbon monoxide $\mathrm{CO}$ and $\mathrm{H}_{2}$ sensors are operated in a variety of challenging environments of industries. Fast response is the critical requirement for theses sensors; therefore, readout mechanism of testing system faces high level of noise signals because detecting device signal at ppm (part per million) level to find the selectivity of these gases is very cumbersome effort. [92] reported the sensitivity issues in ethanol sensors during the device analysis; without readout circuitry interface on chip, these sensors become difficult to characterize.

The packaged devices that have specific environment, any change in the environment, or defective packaging may cause incorrect outcomes and induce additional faulty behavior during testing. In MEMS analysis reported in [93], 
TABLE 5: Destructive and nondestructive techniques for MEMS testing.

\begin{tabular}{|c|c|c|}
\hline Technique & Observation & Mode \\
\hline Optical microscopy & Stains, debris, fracture, and abnormal displacements [52]. & Nondestructive \\
\hline Scanning laser microscopy & Extended depth-of-focus, abnormal vertical displacements [53]. & Nondestructive \\
\hline $\begin{array}{l}\text { Scanning Electron } \\
\text { Microscopy (SEM) }\end{array}$ & Imaging defects at high magnification [54]. & Nondestructive \\
\hline Focused Ion Beam (FIB) & $\begin{array}{c}\text { To image structures, to cross-section elements of concern, and to cut } \\
\text { elements free for subsequent examination [55]. }\end{array}$ & Destructive \\
\hline Laser-Doppler Vibrometer & To measure out of plane motion [56]. & Nondestructive \\
\hline $\begin{array}{l}\text { Computed tomography } \\
\text { (CT) }\end{array}$ & Visualizing 3D internal structures [57]. & Nondestructive \\
\hline Interferometry & To detect the tilt or deflection of a sample [58]. & Nondestructive \\
\hline $\begin{array}{l}\text { Transmission electron } \\
\text { microscopy (TEM) }\end{array}$ & To observe thin films deposited on MEMS [59]. & Nondestructive \\
\hline $\begin{array}{l}\text { Energy dispersive X-ray } \\
\text { spectroscopy (EDS) }\end{array}$ & To analyze chemical composition of surface coating [60]. & Nondestructive \\
\hline $\begin{array}{l}\text { Wavelength dispersive } \\
\text { X-ray spectroscopy (WDS) }\end{array}$ & To analyze chemical composition of surface coating [61]. & Nondestructive \\
\hline $\begin{array}{l}\text { Atomic force microscopy } \\
\text { (AFM) }\end{array}$ & Topographic images and surface traces [62]. & Nondestructive \\
\hline $\begin{array}{l}\text { Auger electron } \\
\text { spectroscopy (AES) }\end{array}$ & $\begin{array}{l}\text { To perform qualitative and semiquantitative compositional analysis of } \\
\text { surface of materials [63]. }\end{array}$ & Nondestructive \\
\hline $\begin{array}{l}\text { Secondary ion mass } \\
\text { spectroscopy (SIMS) }\end{array}$ & $\begin{array}{l}\text { Compositional analysis of the sample with sensitivities in ppm to ppb, } \\
\text { removing material from the device [64]. }\end{array}$ & Destructive \\
\hline $\begin{array}{l}\text { Thermally induced voltage } \\
\text { alteration (TIVA) }\end{array}$ & To identify electrical failure mode [65]. & Nondestructive \\
\hline $\begin{array}{l}\text { Resistive contrast imaging } \\
(\mathrm{RCI})\end{array}$ & To identify electrical failure mode [66]. & Nondestructive \\
\hline Infrared Microscopy & $\begin{array}{l}\text { To construct thermal images based on the infrared radiance emitted } \\
\text { from the structures [67]. }\end{array}$ & Nondestructive \\
\hline Light emission & To observe MEMS optical devices [68]. & Nondestructive \\
\hline Acoustic emission & To observe running device within package [69]. & Nondestructive \\
\hline Laser cutting & To impart elements of device such as gears and links [70]. & Destructive \\
\hline Lift-off technique & Accumulation of wear debris at the surfaces [71]. & Nondestructive \\
\hline
\end{tabular}

lid removing changed the device environment and caused change in functionality. It was observed that device had to face the malfunctioning due to contaminant particles, environmental change, and other potential defects.

MEMS actuators [94, 95] generate power using any electrical or physical stimulus. These mechanical components generate power and motion for other MEMS components. A variety of devices, for example, BioMEMS, RF MEMS, microfluidic, or optical MEMS, need some forms of actuations to interact with another microstructure, in moving a fluid or a micromirror. MEMS actuators are stimulated under different electrical domains. Electrothermal actuators exploit heat producing due to power dissipation in the device. The increase in temperature causes expansion in the structure; then, necessary displacement is induced for motion. In electrostatic actuators [96], electric field is involved to attract other parts of device to generate motion. Prevailing fault modes of stiction [97] and particle contamination were observed in both thermal and electrostatic actuators. Actuators can contain rubbing surfaces which may result in formation of wear or debris. The major concerns for testing of MEMS actuators must be nondestructive regarding fault analysis of stiction films and coatings, and functional testing of multiple devices in parallel. Every type of actuator may have distinctive failure mechanisms and tribulations for fault analysis.

Thermal actuators face the typical fault mechanisms of thermal degradation $[112,113]$. The side effects of electrothermal cycles in these devices are under observations. Faults under stress [114] were analyzed by introducing permanent deformation in the mechanical structure. Structural defect is produced out of plane nonlinear motion of thermal actuator and due to increase in temperature; actuator was welded to the substrate. Analyzing thermal behavior of dynamic structures is a difficult task. Techniques involved in generating thermal actuations were destructive; they slowed down the motion of actuator. The significance of understanding heating effect of a thermal actuator and occurrence of localized heat can support thermal behavior modeling and reduce the fault mechanisms. 
TABLE 6: Common testing issues in different category of MEMS devices.

\begin{tabular}{ll}
\hline Category & Source of failure \\
\hline & \\
RF MEMS & \\
Switches, & Stiction failure, \\
resonators, & surface \\
lab-on-chip, & contaminations, and \\
capacitor, & accumulation of \\
varactor, & charges in the \\
sensors, and & dielectric part. \\
filters. &
\end{tabular}

Testing issues

device stick to one another.

Major issue was because leftover charge

in the dielectric causes increase in voltage

required for the device actuation and

signal transmission.

Other issues of catastrophic failure

occurred due to constant increase in

voltage that causes the dielectric

breakdown.

Crack initiated due to high stress in the structure.

Breakage of structure due to impact with the substrate.

$\begin{array}{ll}\text { Optical } & \\ \text { MEMS } & \text { High surface } \\ \text { Sensor, } & \text { roughness, } \\ \text { resonator, } & \text { stiction, and } \\ \text { optical } & \text { accumulation of } \\ \text { buffers, } & \text { charges. } \\ \text { mirrors and } & \\ \text { filters } & \end{array}$

Roughness of micromirror surface, stiction due to the accumulation of charges that caused stuck in actuation. Tracing faults of shorts and stiction beneath the mirror surface. Cracks initiated during detachment of the micromirror while doing failure analysis under the mirror surface.

Structure breakage during handling.
Observations

A challenge in RF MEMS testing was to analyze stiction failure nondestructively.

Tracing the genuine adhesion point without removal of any part or component was challenging. Hillocks and high roughness of contact area created gap between contact surfaces.

Issues about contact area, geometry and the asperity in contact area were highlighted to understand RF MEMS [98-101].

Surface roughness of single mirror was determined feasibly and it takes time for analysis of various mirror locations.

The surface roughness analysis of arrays of mirrors was not reasonable using current AFM techniques. Parallel test technique provided satisfactory results in determining surface roughness of entire array or collection of mirrors [102-104].

During typical analysis using SEM, the device was flushed of fluid before analysis.

High quality resolution was

Device was flushed of fluid before analysis; this effort negotiated the failure

Fluid contamination,

Microfluidics leakage, mechanism and induce erroneous outcomes.

no compatibility with MEMS, flow sensors, micro channel, and micro needles. short-circuit defect, and catastrophic and parametric faults due to structural defects.
The common issues are fluid contamination, deprocessing, leak detection and compatibility with MEMS. The fluid flowing under electrostatic domain was stuck due to opposite charged molecules causes channel blockage.

Channel with the rough walls caused a turbulent flow of fluid sample. required for microfluidic systems during an analysis of pressure or flow sensor exclusive of flushing the device.

Therefore in verification of device functionality, purpose of using test fluid was helpful in tracing the movement of the fluid during operation. The approach of using diagnostic fluid also proved helpful to trace the breakage, leakage or cracks in the device [105-108].

\begin{tabular}{|c|c|c|c|}
\hline $\begin{array}{l}\text { BioMEMS } \\
\text { Lab-on-chip, } \\
\text { biosensors. }\end{array}$ & $\begin{array}{l}\text { Fluid contamination, } \\
\text { leakage, } \\
\text { blockage of channel, } \\
\text { cracks, } \\
\text { and material } \\
\text { compatibility. }\end{array}$ & $\begin{array}{l}\text { Analogous tribulations with the existence } \\
\text { of additional biological materials was } \\
\text { experienced during testing. } \\
\text { In the analysis of DNA purification, the } \\
\text { surface area of channel was limited. } \\
\text { Sample clogging occurs in the channel } \\
\text { during testing [109-111]. }\end{array}$ & $\begin{array}{l}\text { Challenges of functional testing } \\
\text { were device deprocessing and } \\
\text { biocompatibility. }\end{array}$ \\
\hline
\end{tabular}

Electrostatic actuators typically have single cantilever, bridge, or two sets of comb fingers; the actuator is derived due to the change in polarity of the electric fields at the opposite fingers. Releasing of multistructure MEMS devices [115] is also a challenging job; occurrence of structural defects in comb fingers was found as one of the origins of failure. Rapid identification of failure mechanism of microstructures is essential. Table 6 briefly describes the failure analysis reported for different categories of MEMS devices.

\section{Issues in Parallel Testing}

In the previous research work, a lot of discussions $[16,88,116-$ $121]$ have been made to cope with the challenges and issues in 


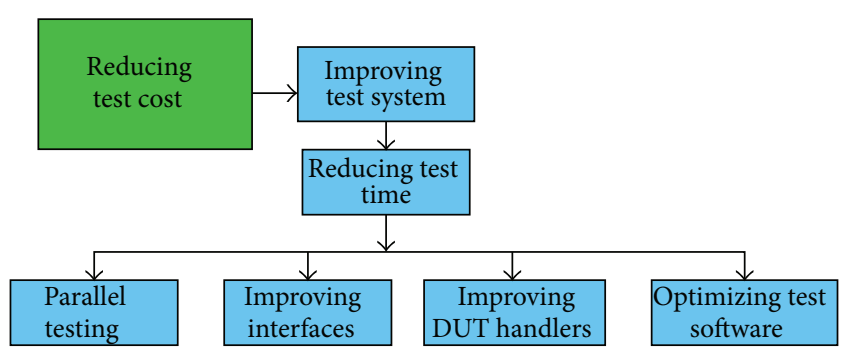

Figure 2: Efforts of reducing MEMS testing cost.

MEMS testing and its requirement. MEMS final testing has limited visibility in the literature from industries that have successfully manufactured MEMS devices such as humidity sensors, pressure sensors, and magnetic field sensor. This type of trend shows an indication of custom nature of test for MEMS. According to MIG's (MEMS Industry Group) METRIC (MEMS Technology Roadmap and Industry Congress) $[20,122]$, there are no agreed testing standards and this is the major limitation for the industries growth and innovation. The flow chart in Figure 2 shows the efforts of developing and improving the MEMS test systems to reduce the cost of testing.

A very few test systems are commercially available [123] and are limited to test specific commercial devices, that is, accelerometers, gyroscope, pressure sensors, microphones, combo sensor, proximity sensor, and magnetic sensor. This section discusses the limitation and issues of test systems reported in literature. An attempt was made by Maudie et al. [124] to improve ATE (Automated Test Equipment) for testing accelerometers in parallel. Variations in electrical parameters occurred from device to device in case of producing MEMS devices in bulk. ATE was unable to perform proper calibration of these devices due to lack of modularity and flexibility. ATE was improved by changing electrical and nonelectrical interfaces of DUT (device under test). Moreover, these efforts and test system were limited to accelerometers only.

Various approaches to test MEMS optical devices and flow sensors were reported by Kerkhoff [10]. Packaging of flow sensor altered the device specifications due to change in environment. The test system had to face issues in handling mechanism of nonelectric input for flow sensor. That increased the testing time; therefore, test handlers required improvement to reduce test time and to enhance parallelism. This test system was limited to the specific devices. Chen reported an effort of improving traditional test system in [125]. The technique was able to test only 16 devices (motion sensors) in parallel. They used the QSPI (quad serial port interface) to enhance the parallelism. However, test system had to face the high noise effects in case of enhancing parallelism. [126] presented a test methodology for microfluidics biochips using linear programming model. They investigated the problems in detection catastrophic faults in these devices. They tried to minimize the test time through linear programming model.

A case study based on accelerometers testing was introduced by Ciganda et al. [127]. In conventional tester, interfaces of DUTs were connected through wires, which were being stretched and twisted due to mechanical movement of test stage. Some DUTs suffered through the lack of signal communication during testing process, resulting in raising the test time and reducing the parallelism. Then, an enhanced architecture was proposed which was able to implement calibration and testing process by hardware, serial interface module (SIM), reducing the amount of tester internal wires. In [128], Ciganda Brasca et al. also used the FPGA technique in conventional testing machine of MEMS devices. Lengthy communication distance and wires between tester and DUT interface were the limiting issues in ATE, tending to limit the electrical stimulation frequency, which ultimately slowed down the test process. High testing parallelism was achieved to overcome such limitations using FPGA module. This technique was used on commercial gyroscopes and accelerometers.

Several MEMS test systems introduced by [129] have the ability to test multiple MEMS applications like accelerometer, gyroscope, pressure sensor, magnetic sensor, and microphone. These systems are capable of testing the devices in parallel. Schaeffel et al. in [130] introduced the design of interferometry test station for parallel testing of optical MEMS. They tested up to 100 DUTs simultaneously through this inspection technique, as optical test systems had the ability to test devices serially, which consumed a lot of testing time and costs. Another technique was reported by Oesterle et al. [131] for a massive parallel test of MEMS microphones. A reconstruction method was adopted by utilizing techniques of tomographic imaging. The specific parameters of all parallel connected DUTs are superimposed through one signal and the DUT response was read out with the reference of single measurement of device.

Testing of single MEMS device is also a challenging task; it is drastically escalated in cost in case of simultaneous testing of multiple devices. The cost of test station for high volume production can accede to millions of dollars. The main tools for these test systems are common including physical, electri$\mathrm{cal}$, and temperature stimulus. The modular fixtures perform different measurements (acceleration, pressure, etc.). These modular testers are basic requirement for the industries. Figure 3 shows a general schematic of MEMS tester. Most of efforts are being emphasized on modification of conventional test systems. Issues in parallel testing are summarized as follows:

(i) There is lack of signal communication when a number of DUTs are increased to an extent.

(ii) Noise level is increased with the increase in test sockets.

(iii) One type of devices is tested at one time.

(iv) DUT handler has to modify if device is different.

(v) There is limitation of test coverage.

(vi) Test algorithms are different for dissimilar devices. 


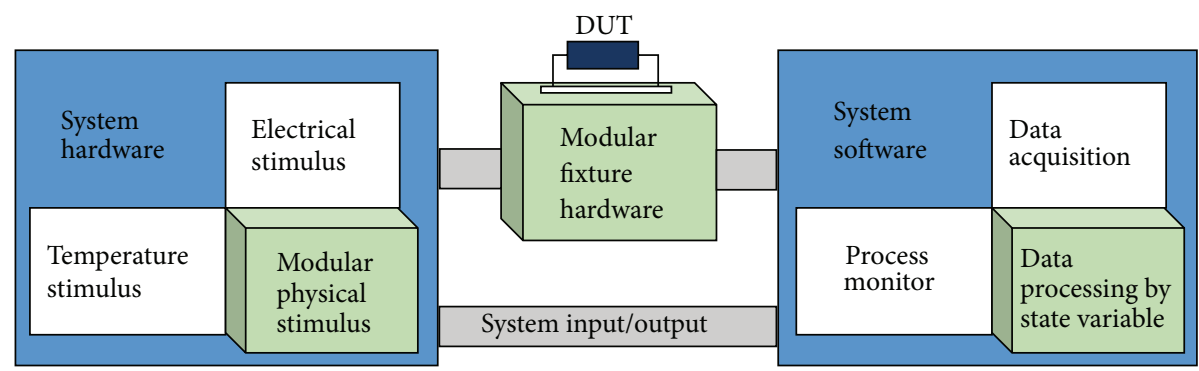

FIGURE 3: Generic MEMS testing system [37].

(vii) Different test programs have to be designed for electrical and mechanical domains.

(viii) Test redundancy is required in case of simultaneous fault detection of multiple DUTs.

The test systems reported in this section utilize both electrical and nonelectrical stimuli for final testing and calibration. But the nonelectrical stimuli such as humidity, pressure, and motion are intrinsically slower than electrical signals and, as a result, they take long test time and they also affected the cost. Ongoing changes in MEMS market are the warnings for future testing issues and challenges. A lack of test standards [122] has a negative indirect effect on the business of MEMS. There is still need of cost-effective parallel test methodology. Testing imposes large direct costs on the product as test equipment is expensive and test programs are limited to test specific devices.

\section{Conclusion}

MEMS devices are enormously dissimilar in their application and function. Various limited tools and techniques leveraged from the IC technology are being utilized in MEMS testing; however, there is need of developing new test tools for the diagnosis of different faults. Several classes of devices discussed in this literature have common issues related to MEMS testing. MEMS can only be penetrated as an emerging technology until the cost of testing is reduced substantially and valued added technique is applied at the early stage of the market. MEMS testing is fetching difficult challenges, for the reason that conventional electrical testing is unable to comprehend the mechanical behavior of a MEMS device. In addition, mechanical behavior requires different technique to test it (e.g., flow, movement, and pressure). Therefore, integration of multifunction in devices increases the testing problems as a function of the device complexity. Techniques of MEMS testing are different in development processes, that is, design, prototype, and production. The Design for Test (DFT) is becoming a paramount as MEMS designers are facing the pressure of more cost and time-to-market. In the design phase, it is essential to know the requirements of device testing and it should be cost-effective and reliable as a predictor of device performance.

\section{Conflict of Interests}

The authors declare that there is no conflict of interests regarding the publication of this paper.

\section{Acknowledgments}

The authors would like to thank GA funding scheme as well as the Department of Electrical \& Electronic Engineering of Universiti Teknologi PETRONAS.

\section{References}

[1] K. Singh, S. Akhtar, S. Varghese, and J. Akhtar, "Design and development of MEMS pressure sensor characterization setup with low interfacing noise by using NI-PXI system," in Physics of Semiconductor Devices, V. K. Jain and A. Verma, Eds., pp. 449451, Springer, Berlin, Germany, 2014.

[2] J. Dennis, A. Ahmed, and M. Khir, "Fabrication and characterization of a CMOS-MEMS humidity sensor," Sensors, vol. 15, no. 7, pp. 16674-16687, 2015.

[3] A. Hasan, M. Nurunnabi, M. Morshed et al., "Recent advances in application of biosensors in tissue engineering," BioMed Research International, vol. 2014, Article ID 307519, 18 pages, 2014.

[4] R. Ramadoss, R. Dean, and X. Xiong, "Chapter 13: MEMS testing," in System-on-Chip Test Architectures, pp. 591-651, Morgan Kaufmann, Burlington, Mass, USA, 2008.

[5] K. K. Lee and B. C. Kim, "MEMS spring probe for next generation wafer level testing," in Proceedings of the International Conference on MEMS, NANO and Smart Systems, pp. 214-217, IEEE, Alberta, Canada, July 2003.

[6] K. Hyunho, Y. Yongdeuk, C. Sanghyun, L. Jun, Y. Soongyu, and Y. Sung, "RF multi-DUT testing technology for RF WLP," in Proceedings of the 2nd Electronics System-Integration Technology Conference (ESTC'08), pp. 547-550, Greenwich, UK, September 2008.

[7] B. Deng and W. Glauert, "Formal description of test specification and ATE architecture for mixed-signal test," in Proceedings of the International Test Conference (ITC '04), pp. 1081-1090, IEEE, Charlotte, NC, USA, October 2004.

[8] H. Farahani, J. K. Mills, and W. L. Cleghorn, "Design, fabrication and analysis of micromachined high sensitivity and $0 \%$ cross-axis sensitivity capacitive accelerometers," Microsystem Technologies, vol. 15, no. 12, pp. 1815-1826, 2009. 
[9] H. Liu, S. Gao, X. Liang, and L. Jin, "Performance analysis and measurement of micro-machined gyroscope," in Proceedings of the 9th International Conference on Electronic Measurement and Instruments (ICEMI '09), pp. 130-134, Beijing, China, August 2009.

[10] H. G. Kerkhoff, "Testing of MEMS-based microsystems," in Proceedings of the 10th IEEE European Test Symposium (ETS '05), pp. 223-228, IEEE, Tallinn, Estonia, May 2005.

[11] V. Skvortzov, C. Yong Chul, L. Byeung-Leul, and S. Cimoo, "Development of a gyro test system at Samsung Advanced Institute of Technology," in Proceedings of the Position Location and Navigation Symposium (PLANS '04), pp. 133-142, Monterey, Calif, USA, April 2004.

[12] Z. Liang and J. Zhang, "A dynamic balance testing framework for gyroscope based on embedded system," in Proceedings of the International Conference on Artificial Intelligence and Computational Intelligence (AICI '09), pp. 573-577, IEEE, Shanghai, China, November 2009.

[13] T.-R. Hsu, Lectures on MEMS and Microsystem Design and Manufacture, Department of Mechanical and Aerospace Engineering, San Jose State University, San Jose, Calif, USA, 2011.

[14] B. Moyer, “The MEMS Testing Quagmire," April 2011, http:// www.eejournal.com/archives/articles/20111219-mems/.

[15] C. G. Masi, “Testing the MEMS revolution,” June 2004, http:// www.tmworld.com/design/design-and-prototyping/4379894/ Testing-the-MEMS-revolution.

[16] M. F. Cortese and G. Avenia, "MEMS testing: innovations in mass production," August 2010, http://www2.electronicproducts .com/MEMS_testing_innovations_in_mass_production-articlefarc_stmicro_jul2010-html.aspx.

[17] Texas Instruments DLP, “Reverse Costing Analysis," 2013, http://www.systemplus.fr/wp-content/uploads/2013/05/S+C_ RM106_-Texas-Instruments-DLP-Pico-family-_Sample.pdf.

[18] MEPTEC, "State-of-the-art MEMS testing and reliability strategies," in Proceedings of the MEMS Testing \& Reliability Conference, Santa Clara, Calif, USA, 2011.

[19] S. Wynnyckyj, "MEMS testing challenges \& cost of test," in Proceedings of the 13th Annual MEPTEC MEMS Technology Symposium, San Jose, Calif, USA, May 2015.

[20] H. Bennett, M. Gaitan, and Y. Obeng, MEMS Testing Standards: A Path to Continued Innovation, MEMS Industry Group, Pittsburgh, Pa, USA, 2011.

[21] V. Henttonen, "Heading for more cost efficient testing of MEMS," in Proceedings of the 14th Europeon Manufacturing Test Conference (EMTC '12), Dresden, Germany, October 2012.

[22] K. Lightman, MEMS and Sensor Trends, MEMS Industry Group, 2013.

[23] S. Delgado, "Parallel testing techniques for optimizing test program execution and reducing test time," in Proceedings of the IEEE AUTOTESTCON, pp. 439-441, IEEE, Salt Lake City, Utah, USA, September 2008.

[24] E. H. Volkerink, A. Khoche, J. Rivoir, and K. D. Hilliges, “Test economics for multi-site test with modern cost reduction techniques," in Proceedings of the 20th IEEE VLSI Test Symposium (VTS '02), pp. 411-416, Monterey, Calif, USA, 2002.

[25] T. Adachi, A. Pramanick, and M. Elston, "Parallel, multi-DUT testing in an open architecture test system," in Proceedings of the IEEE International Test Conference ( ITC '05), p. 890, Austin, Tex, USA, November 2005.

[26] A. Hakan Baba and K. S. Kim, Framework for Massively Parallel Testing at Wafer and Package Test, 2009, http://iccd.et.tudelft.nl/ 2009/proceedings/328Baba.pdf.
[27] J.-H. Zhang, D.-G. Li, and X.-J. Cui, "Failure analysis of microstructure under shock load," in Proceedings of International Conference on Modelling, Identification \& Control (ICMIC '12), pp. 86-90, IEEE, June 2012.

[28] D. M. Pierce, B. Zeyen, B. M. Huigens, and A. M. Fitzgerald, "Predicting the failure probability of device features in MEMS," IEEE Transactions on Device and Materials Reliability, vol. 11, no. 3, pp. 433-441, 2011.

[29] D. Lellouchi, X. Lafontan, J. Dhennin, F. Beaudoin, and F. Pressecq, "MEMS failure analysis case studies using the IROBIRCH method-short circuit localization in a MEMS pressure sensor," in Proceedings of the 16th IEEE International Symposium on the Physical and Failure Analysis of Integrated Circuits (IPFA '09), pp. 827-831, Suzhou, China, July 2009.

[30] A. Broué, J. Dhennin, C. Seguineau et al., "Methodology to analyze failure mechanisms of ohmic contacts on MEMS switches," in Proceedings of the IEEE International Reliability Physics Symposium (IRPS '09), pp. 869-873, IEEE, Montreal, Canada, April 2009.

[31] De Wolf, A. Jourdain, P. De Moor, H. A. C. Tilmans, and L. Marchand, "Hermeticity testing and failure analysis of MEMS packages," in Proceedings of the 14th International Symposium on the Physical and Failure Analysis of Integrated Circuits (IPFA '07), pp. 147-154, IEEE, Bangalore, India, July 2007.

[32] J. A. Walraven, "Future challenges for MEMS failure analysis," in Procedeings of the IEEE International Test Conference (ITC '03), vol. 1, pp. 850-855, Washington, DC, USA, October 2003.

[33] B. Courtois, S. Mir, B. Charlot, and B. Lubaszewski, "From microelectronics to MEMS testing," in Proceedings of the IEEE Microelectronics Reliability and Qualification Workshop, Glendale, Calif, USA, October-November 2000.

[34] M. T. Jan, N. H. B. Hamid, M. H. B. M. Khir, M. Shoaib, and A. Mirza, "Influence of crack growths on the performances of cantilever based MEMS devices: design and simulations," in Proceedings of the 5th International Conference on Intelligent and Advanced Systems (ICIAS '14), pp. 1-4, Kuala Lumpur, Malaysia, June 2014.

[35] M. Al-Fandi, J.-W. Kim, A. P. Malshe, S. Tung, J. Jenkins, and R. Pooran, "Chemo-sensitivity and reliability of flagellar rotary motor in a MEMS microfluidic actuation system," Sensors and Actuators B: Chemical, vol. 114, no. 1, pp. 229-238, 2006.

[36] X. Xiong, Y.-L. Wu, and W.-B. Jone, "Material fatigue and reliability of MEMS accelerometers," in Proceedings of the 23rd IEEE International Symposium on Defect and Fault Tolerance in VLSI Systems (DFT '08), pp. 314-322, IEEE, Boston, Mass, USA, October 2008.

[37] F. T. Hartley, S. Arney, and F. Sexton, Microsystems Reliability, Test and Metrology, 2001.

[38] M. Bazu, L. Galateanu, and V. E. Ilian, "Reliability accelerated tests for microsystems," in Proceedings of the 34th International Spring Seminar on Electronics Technology (ISSE '11), pp. 182-187, Tatranská Lomnica, Slovakia, May 2011.

[39] J.-N. Hung, H. Hocheng, and K. Sato, "Torsion fatigue testing of polycrystalline silicon cross-microbridge structures," Japanese Journal of Applied Physics, vol. 50, no. 6, Article ID 06GM07, 2011.

[40] A. Bemis, A. Ned, S. Stefanescu, and N. Wilson, "The effect of silicon fatigue on Kulite silicon pressure sensor's reliability," Kulite Proprietary Information AN 101, Kulite, 2012.

[41] J. Li, M. Broas, J. Makkonen, T. T. Mattila, J. Hokka, and M. Paulasto-Kröckel, "Shock impact reliability and failure analysis 
of a three-axis MEMS gyroscope," Journal of Microelectromechanical Systems, vol. 23, no. 2, Article ID 6570572, pp. 347-355, 2014.

[42] C. Patel, P. McCluskey, and D. Lemus, "Performance and reliability of MEMS gyroscopes at high temperatures," in Proceedings of the 12th IEEE Intersociety Conference on Thermal and Thermomechanical Phenomena in Electronic Systems (ITherm '10), pp. 1-5, IEEE, Las Vegas, Nev, USA, June 2010.

[43] H. Kapels, R. Aigner, and J. Binder, "Fracture strength and fatigue of polysilicon determined by a novel thermal actuator [MEMS]," IEEE Transactions on Electron Devices, vol. 47, no. 7, pp. 1522-1528, 2000.

[44] M. van Gils, J. Bielen, and G. McDonald, "Evaluation of creep in RF MEMS devices," in Proceedings of the International Conference on Thermal, Mechanical and Multi-Physics Simulation Experiments in Microelectronics and Micro-Systems (EuroSime '07), pp. 1-6, London, UK, April 2007.

[45] Q. Min, J. Tao, Y. Zhang, and X. Chen, "A parallel-plate actuated test structure for fatigue analysis of MEMS," in Proceedings of the International Conference on Quality, Reliability, Risk, Maintenance, and Safety Engineering (ICQR2MSE '11), pp. 297301, Xi'an, China, June 2011.

[46] K. Hei, V. Pott, R. Nathanael, J. Jaeseok, E. Alon, and L. TsuJae King, "Design and reliability of a micro-relay technology for zero-standby-power digital logic applications," in Proceedings of the IEEE International Electron Devices Meeting (IEDM '09), pp. 1-4, Baltimore, Md, USA, December 2009.

[47] M. Tariq Jan, N. Hisham Bin Hamid, M. H. Md Khir, K. Ashraf, and M. Shoaib, "Reliability and fatigue analysis in cantileverbased MEMS devices operating in harsh environments," Journal of Quality and Reliability Engineering, vol. 2014, Article ID 987847, 16 pages, 2014.

[48] D. Mardivirin, A. Pothier, M. E. Khatib, A. Crunteanu, O. Vendier, and P. Blondy, "Reliability of dielectric less electrostatic actuators in RF-MEMS ohmic switches," in Proceedings of the 38th European Microwave Conference (EuMC '08), pp. 15171520, IEEE, Amsterdam, The Netherlands, October 2008.

[49] F. Bölöni, A. Benabou, and A. Tounzi, "Stochastic modeling of the pull-in voltage in a MEMS beam structure," in Proceedings of the 14th Biennial IEEE Conference on Electromagnetic Field Computation (CEFC '10), p. 1, Chicago, Ill, USA, May 2010.

[50] Y. Huang, A. S. S. Vasan, R. Doraiswami, M. Osterman, and M. Pecht, "MEMS reliability review," IEEE Transactions on Device and Materials Reliability, vol. 12, no. 2, pp. 482-493, 2012.

[51] P. Yang and N. Liao, "Surface sliding simulation in microgear train for adhesion problem and tribology design by using molecular dynamics model," Computational Materials Science, vol. 38, no. 4, pp. 678-684, 2007.

[52] B. Potsaid and J. Ting-Yung Wen, "Adaptive scanning optical microscope: large field of view and high-resolution imaging using a MEMS deformable mirror," Journal of Micro/Nanolithography, MEMS, and MOEMS, vol. 7, pp. 9-10, 2008.

[53] C. Bechtel, J. Knobbe, H. Grüger, and H. Lakner, "Large field of view MEMS-based confocal laser scanning microscope for fluorescence imaging," Optik, vol. 125, no. 2, pp. 876-882, 2014.

[54] T. Ichimura, Y. Ren, and P. Kruit, "A large current scanning electron microscope with MEMS-based multi-beam optics," Microelectronic Engineering, vol. 113, pp. 109-113, 2014.

[55] F. Altmann and R. J. Young, "Site-specific metrology, inspection, and failure analysis of three-dimensional interconnects using focused ion beam technology," Journal of
Micro/Nanolithography, MEMS, and MOEMS, vol. 13, no. 1, Article ID 011202, 11 pages, 2014.

[56] J. Janes and U. Hofmann, "Studies on the dynamics of vacuum encapsulated 2D MEMS scanners by laser Doppler vibrometry," in Reliability, Packaging, Testing, and Characterization of MOEMS/MEMS, Nanodevices, and Nanomaterials XIII, vol. 8975 of Proceedings of SPIE, San Francisco, Calif, USA, March 2014.

[57] Z. Niu, H. Suzuki, Y. Ohtake, and T. Michikawa, "Mesh generation of porous metals from X-ray computed tomography volume data," Journal of Mechanical Science and Technology, vol. 28, no. 7, pp. 2445-2451, 2014.

[58] Z. Zhang, Y. Gao, and W. Su, "Laser self-mixing interferometer for MEMS dynamic measurement," Frontiers of Optoelectronics, vol. 6, no. 2, pp. 210-215, 2013.

[59] E. Hosseinian and O. N. Pierron, "Quantitative in situ TEM tensile fatigue testing on nanocrystalline metallic ultrathin films," Nanoscale, vol. 5, no. 24, pp. 12532-12541, 2013.

[60] D. E. Newbury and N. W. M. Ritchie, "Scanning electron microscopy/energy dispersive spectrometry fixedbeam or overscan $\mathrm{x}$-ray microanalysis of particles can miss the real structure: $\mathrm{x}$-ray spectrum image mapping reveals the true nature," in Proceedeings of the Scanning Microscopies: Advanced Microscopy Technologies for Defense, Homeland Security, Forensic, Life, Environmental, and Industrial Sciences, vol. 8729 of Proceedings of SPIE, Baltimore, Md, USA, April 2013.

[61] D. E. Newbury and N. W. M. Ritchie, "Rigorous quantitative elemental microanalysis by scanning electron microscopy/energy dispersive $\mathrm{x}$-ray spectrometry (SEM/EDS) with spectrum processing by NIST DTSA-II," in Scanning Microscopies, vol. 9236 of Proceedings of SPIE, p. 17, 2014.

[62] A. Mohammadi, A. G. Fowler, Y. K. Yong, and S. O. R. Moheimani, "A feedback controlled MEMS nanopositioner for on-chip high-speed AFM," Journal of Microelectromechanical Systems, vol. 23, no. 3, Article ID 6678523, pp. 610-619, 2014.

[63] J. Harris-Jones, E. Stinzianni, C. Lin, V. Jindal, R. Teki, and H. J. Kwon, "Applications of advanced metrology techniques for the characterization of extreme ultraviolet mask blank defects," Journal of Micro/Nanolithography, MEMS, and MOEMS, vol. 12, no. 1, Article ID 013007, 2013.

[64] J. An, J. H. Shim, Y.-B. Kim et al., "MEMS-based thin-film solidoxide fuel cells," MRS Bulletin, vol. 39, no. 9, pp. 798-804, 2014.

[65] R. J. Ross, Microelectronics Failure Analysis Desk Reference, ASM International, 2011.

[66] K. Lambrinou, K. Arstila, T. Hantschel et al. et al., "Towards the understanding of resistive contrast imaging in in-situ dielectric breakdown studies using a nanoprober setup," MRS Online Proceedings Library, vol. 1249, 2010.

[67] S. Lee and H. Yoo, "A near-infrared confocal scanner," Measurement Science and Technology, vol. 25, no. 6, Article ID 065403, 2014.

[68] Y. Takaki, "Micromirrors and 1D scanning produce an enlarged holographic color display," in Illumination \& Displays, Proceedings of SPIE, pp. 1-5, 2014.

[69] A. P. Wright, A multi-axis capacitive mems sensor system for acoustic emission sensing [Ph.D. thesis], Doctor of Philosophy, Civil and Environmental Engineering, Canegei Mellon University, 2009.

[70] P. Romero, N. Otero, I. Coto, C. Leira, A. González, and P. Romero, "Experimental study of diode laser cutting of silicon by means of water assisted thermally driven separation mechanism," Physics Procedia, vol. 41, pp. 617-626, 2013. 
[71] E. Tolstosheeva, E. Barborini, E. M. Meyer, M. Shafi, S. Vinati, and W. Lang, "Micropatterning of nanoparticle films by bilayer lift-off," Journal of Micromechanics and Microengineering, vol. 24, no. 1, Article ID 015001, 2014.

[72] M. Bazu and T. Bajenescu, Failure Analysis, John Wiley and Sons, 2011.

[73] C. Jeffrey, Z. Xu, and A. Richardson, "Using bias superposition to test a thick film conductance sensor," Journal of Physics: Conference Series, vol. 15, no. 1, pp. 161-166, 2005.

[74] N. Islam, Microelectromechanical Systems and Devices, InTech, 2012.

[75] S. Biswas, P. Li, R. D. Blanton, and L. T. Pileggi, "Specification test compaction for analog circuits and MEMS [accelerometer and opamp examples]," in Proceedings of the Design, Automation and Test in Europe, pp. 164-169, IEEE, March 2005.

[76] N. Dumas, Z. Xu, K. Georgopoulos, R. J. T. Bunyan, and A. Richardson, "Online testing of MEMS based on encoded stimulus superposition," Journal of Electronic Testing, vol. 24, no. 6, pp. 555-566, 2008.

[77] K. M. Cheng, Electrostatic testing of simple MEMS structures [M.S. thesis], Department of Electrical and Computer Engineering, University of Manitoba, 2006.

[78] A. Izadian and P. Famouri, "Fault diagnosis of MEMS lateral comb resonators using multiple-model adaptive estimators," IEEE Transactions on Control Systems Technology, vol. 18, no. 5, pp. 1233-1240, 2010.

[79] A. Izadian, P. Khayyer, and P. Famouri, "Fault diagnosis of timevarying parameter systems with application in MEMS LCRs," IEEE Transactions on Industrial Electronics, vol. 56, no. 4, pp. 973-978, 2009.

[80] A. Izadian, "Self-tuning fault diagnosis of MEMS," Mechatronics, vol. 23, no. 8, pp. 1094-1099, 2013.

[81] A. Repchankova, Anti-stiction and self-recovery active mechanisms for high reliability RF-MEMS switches [Ph.D. dissertation], Information and Communication Technologies, University of Trento, 2010.

[82] V. Reppa, Fault detection and diagnosis: application in microelectromechanical systems [Doctoral dissertation], Departement of Electrical and Computer Engineering, University of PATRAS, 2010.

[83] D. Zheng, H. Dagui, D. Zhang, and W. Wu, "An automatic MEMS testing system based on computer microvision," in Proceedings of the IEEE International Conference on Mechatronics and Automation, pp. 854-858, IEEE, Luoyang, China, June 2006.

[84] Y.-J. Pon, C.-H. Shen, and S.-J. Chen, "A low cost high sensitivity CMOS MEMS gas sensor," in Proceedings of the IEEE Instrumentation and Measurement Technology Conference (I2MTC '10), pp. 564-567, Austin, Tex, USA, May 2010.

[85] A. Mirza, N. H. Hamid, M. H. M. Khir et al., "A CMOSMEMS cantilever sensor for capnometric applications," IEICE Electronics Express, vol. 11, no. 9, Article ID 20140113, 2014.

[86] J. G. Ortega, C. L. Tarrida, J. M. Quero et al., "MEMS solar sensor testing for satellite applications," in Proceedings of the Spanish Conference on Electron Devices (CDE '09), pp. 345-348, IEEE, Santiago de Compostela, Spain, February 2009.

[87] Y. Ura, K. Sugano, T. Tsuchiya, and O. Tabata, "Tensile testing of fullerene nano wire using electrostatic MEMS device," in Proceedings of the International Solid-State Sensors, Actuators and Microsystems Conference (TRANSDUCERS '09), pp. 20622065, IEEE, Denver, Colo, USA, June 2009.
[88] R. D. Blanton, “The challenge of MEMS test," in Proceedings of the IEEE International Test Conference, Atlantic City, NJ, USA, 2000.

[89] L. Wang, Y. Hao, Z. Wei, and F. Wang, "A calibration procedure and testing of MEMS inertial sensors for an FPGA-based GPS/ INS system," in Proceedings of the IEEE International Conference on Mechatronics and Automation (ICMA '10), pp. 1431-1436, IEEE, Xian, China, August 2010.

[90] K. Ghose and H. R. Shea, "Fabrication and testing of a MEMS based earth sensor," in Proceedings of the 15th International Conference on Solid-State Sensors, Actuators and Microsystems (TRANSDUCERS '09), pp. 327-330, Denver, Colo, USA, June 2009.

[91] N.-Y. Kim, Y.-H. Kim, Y. Yoon, H.-H. Im, R. K. Y. Choi, and Y. H. Lee, "Correcting air-pressure data collected by MEMS sensors in smartphones," Journal of Sensors, vol. 2015, Article ID 245498, 10 pages, 2015.

[92] M.-Z. Yang and C.-L. Dai, "Ethanol microsensors with a readout circuit manufactured using the CMOS-MEMS technique," Sensors, vol. 15, no. 1, pp. 1623-1634, 2015.

[93] A. Hartzell and M. da Silva, "Reliability issues in miniaturized sensors: importance of standards. What is needed?" in Proceedings of the IEEE Sensors, p. 44, Atlanta, Ga, USA, October 2007.

[94] L. Li, "Applications of MEMS actuators in micro/nano robotic manipulators," in Proceedings of the 2nd International Conference on Computer Engineering and Technology (ICCET '10), vol. 2, pp. 649-652, IEEE, Chengdu, China, April 2010.

[95] M. Kaltenbacher and H. Köck, "Simulation environment for MEMS sensors and actuators," in Proceedings of the 12th International Conference on Thermal, Mechanical and MultiPhysics Simulation and Experiments in Microelectronics and Microsystems (EuroSimE '11), pp. 1/6-6/6, Linz, Austria, April 2011.

[96] J. J. Ruan, N. Monnereau, D. Trémouilles et al., "An accelerated stress test method for electrostatically driven MEMS devices," IEEE Transactions on Instrumentation and Measurement, vol. 61, no. 2, pp. 456-461, 2012.

[97] X. J. Liang and S. Q. Gao, "The adhesion failure analysis of the MEMS gyroscope with comb capacitor," in Proceedings of the 8th International Conference on Reliability, Maintainability and Safety (ICRMS '09), pp. 1234-1236, IEEE, Chengdu, China, July 2009.

[98] R. R. Mansour, "RF MEMS-CMOS device integration: an overview of the potential for RF researchers," IEEE Microwave Magazine, vol. 14, no. 1, pp. 39-56, 2013.

[99] A. Tazzoli, V. Peretti, R. Gaddi, A. Gnudi, E. Zanoni, and G. Meneghesso, "Reliability issues in RF-MEMS switches submitted to cycling and ESD test," in Proceedings of the 44th Annual IEEE International Reliability Physics Symposium (IRPS '06), pp. 410-415, IEEE, San Jose, Calif, USA, March 2006.

[100] N. Sepulveda and M. Toledo-Quinones, "Electrostatic and piezoelectric testing methods for RF MEMS resonators," in Proceedings of the 49th IEEE International Midwest Symposium on Circuits and Systems (MWSCAS '06), vol. 1, pp. 405-409, IEEE, San Juan, Puerto Rico, August 2006.

[101] V. Schirosi, G. Del Re, L. Ferrari, P. Caliandro, L. Rizzi, and G. Melone, "A novel manufacturing technology for RF MEMS devices on ceramic substrates," Journal of Sensors, vol. 2010, Article ID 625325, 6 pages, 2010.

[102] D. Khalil, "Recent trends in optical MEMS for telecommunication applications," in Proceedings of the 49th IEEE International 
Midwest Symposium on Photonics and Its Application, pp. 56-81, Giza, Egypt, May 2004.

[103] T. Zhou, P. Wright, J. Crawford, G. McKinnon, and Y. Zhang, "MEMS 3D optical mirror/scanner," in Proceedings of the International Conference on MEMS, NANO and Smart Systems, pp. 222-226, Banff, Canada, July 2003.

[104] R. Ranganathan, G. Sivakumar, R. Gale, and T. Dallas, "Characterization of stiction accrual in a MEMS," Journal of Microelectromechanical Systems, vol. 18, no. 5, pp. 1149-1159, 2009.

[105] R. B. Fair, A. Khlystov, T. D. Tailor et al., "Chemical and biological applications of digital-microfluidic devices," IEEE Design \& Test of Computers, vol. 24, no. 1, pp. 10-24, 2007.

[106] I.-Y. Lee, T.-P. Hsu, W. W. Wang et al., "Failure analysis of a MEMS micro-injector printing head," in Proceedings of the 14th International Symposium on the Physical and Failure Analysis of Integrated Circuits (IPFA '07), pp. 112-115, IEEE, Bangalore, India, July 2007.

[107] S. Millar and M. Desmulliez, "MEMS ultra low leak detection methods: a review," Sensor Review, vol. 29, no. 4, pp. 339-344, 2009.

[108] D. Mitra, S. Ghoshal, H. Rahaman, K. Chakrabarty, and B. B. Bhattacharya, "Testing of digital microfluidic biochips using improved eulerization techniques and the Chinese postman problem," in Proceedings of the 19th IEEE Asian Test Symposium (ATS '10), pp. 111-116, IEEE, Shanghai, China, December 2010.

[109] A. C. R. Grayson, R. S. Shawgo, A. M. Johnson et al., "A BioMEMS review: MEMS technology for physiologically integrated devices," Proceedings of the IEEE, vol. 92, no. 1, pp. 6-21, 2004.

[110] S. Yang, "Special issue on BioMEMS," Biomedical Engineering Letters, vol. 2, no. 2, pp. 69-70, 2012.

[111] D. R. Tokachichu and B. Bhushan, "Bioadhesion of polymers for BioMEMS," IEEE Transactions on Nanotechnology, vol. 5, no. 3, pp. 228-231, 2006.

[112] J.-H. Lim, Keon-Kuk, S.-J. Shin et al., "Investigation of reliability problems in thermal inkjet printhead," in Proceedings of the 42nd Annual IEEE International Reliability Physics Symposium Proceedings, pp. 251-254, IEEE, Phoenix, Ariz, USA, April 2004.

[113] M. T. Jan, F. Ahmad, N. H. B. Hamid, M. H. B. Md Khir, K. Ashraf, and M. Shoaib, “Temperature dependent Young's modulus and quality factor of CMOS-MEMS resonator: modelling and experimental approach," Microelectronics Reliability, 7 pages, 2015.

[114] W.-K. Jeung, S.-M. Choi, and Y.-J. Kim, "Large displacement polymer bimorph actuator for out-of-plane motion," Journal of Electrical Engineering \& Technology, vol. 1, no. 2, pp. 263-267, 2006.

[115] D. Fernández, J. Ricart, and J. Madrenas, "Experiments on the release of CMOS-micromachined metal layers," Journal of Sensors, vol. 2010, Article ID 937301, 7 pages, 2010.

[116] T. Sviridova, M. Lobur, U. Marikutsa, and D. Korpyljov, "MEMS testing: goals and needs," in Proceedings of the International Conference in Modern Problems of Radio Engineering, Telecommunications and Computer Science (TCSET '06), pp. 442-443, IEEE, Lviv-Slavsko, Ukraine, March 2006.

[117] H. G. Kerkhoff, "Microsystem testing: challenge or common knowledge," in Proceedings of the 7th Asian Test Symposium (ATS '98), pp. 510-511, Singapore, December 1998.

[118] M. Lubaszewski, E. F. Cota, and B. Courtois, "Microsystems testing: an approach and open problems," in Proceedings of the Design, Automation and Test in Europe, pp. 524-528, IEEE, Paris, France, February 1998.
[119] L. G. Salmon, "Testing requirements for microelectromechanical systems (MEMS)," in Proceedings of the IEEE Systems Readiness Technology Conference (AUTOTESTCON '98), p. 160, IEEE, Salt Lake City, Utah, USA, August 1998.

[120] T. Sviridova, Y. Kushnir, and D. Korpyljov, "An overview of MEMS testing technologies," in Proceedings of the 2nd International Conference on Perspective Technologies and Methods in MEMS Design (MEMSTECH '06), pp. 15-18, Lviv, Ukraine, May 2006.

[121] A. Kolpekwar and R. D. Blanton, "Development of a MEMS testing methodology," in Proceedings of the International Test Conference, pp. 923-931, Washington, DC, USA, November 1997.

[122] R. H. Grace, H. Bearsley, M. Gaitan, K. Lightman, R. Subramaniam, and P. Trio, "The role of standards in MEMS commercialization," Chip Scale Review, vol. 19, pp. 21-25, 2015.

[123] SPEA, Integrated MEMS/Sensors Test Cells, 2015.

[124] T. Maudie, A. Hardt, R. Nielsen, D. Stanerson, R. Bieschke, and M. Miller, "Mems manufacturing testing: an accelerometer case study," in Proceedings the International Test Conference, pp. 843849, IEEE, October 2003.

[125] B. B. Chen, "The Most Effective and Lowest Cost MEMS Test Solution," April 2011, http://www.pxisa.org/files/The\%20Most \%20Effective\%20and\%20Lowest\%20Cost\%20MEMS\%20Test $\% 20$ Solution.pdf.

[126] F. Su, S. Ozev, and K. Chakrabarty, "Concurrent testing of droplet-based microfluidic systems for multiplexed biomedical assays," in Proceedings of the International Test Conference (ITC '04), pp. 883-892, IEEE, Charlotte, NC, USA, October 2004.

[127] L. Ciganda, P. Bernardi, M. S. Reorda, D. Barbieri, M. Straiotto, and L. Bonaria, "A tester architecture suitable for MEMS calibration and testing," in Proceedings of the 41st IEEE International Test Conference (ITC '10), p. 1, IEEE, Austin, Tex, USA, November 2010.

[128] L. M. Ciganda Brasca, P. Bernardi, M. Sonza Reorda et al., "A parallel tester architecture for accelerometer and gyroscope MEMS calibration and test," Journal of Electronic Testing, vol. 27, no. 3, pp. 389-402, 2011.

[129] Multitest, “Sensor test," June 2012, http://multitest.com/sensor/.

[130] C. Schaeffel, S. Michael, R. Paris et al., "Design of an interferometric test station for parallel inspection of MEMS," in Proceedings of the 56th International Scientific Colloquium, Ilmenau University of Technology, September 2011.

[131] F. Oesterle, R. Weigel, and A. Koelpin, "A new approach on MEMS sensor batch testing using an analogue parallel test methodology for massive reduction of test time," in Proceedings of the 12th IEEE SENSORS Conference, IEEE, Baltimore, Md, USA, November 2013. 


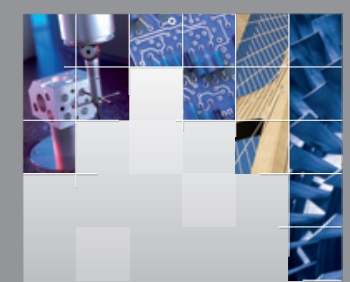

\section{Enfincering}
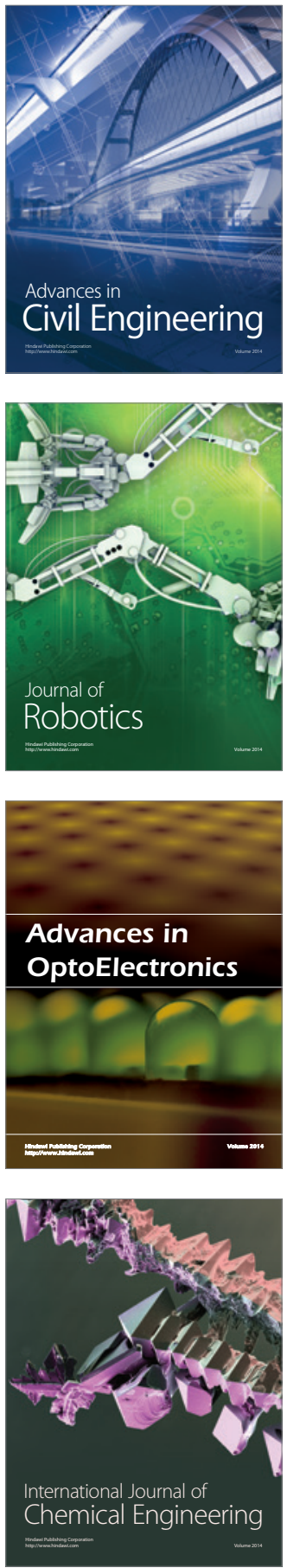

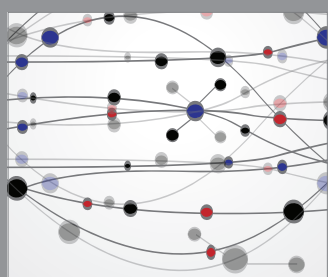

The Scientific World Journal

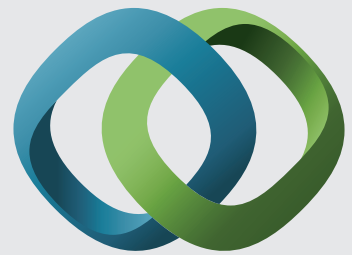

\section{Hindawi}

Submit your manuscripts at

http://www.hindawi.com
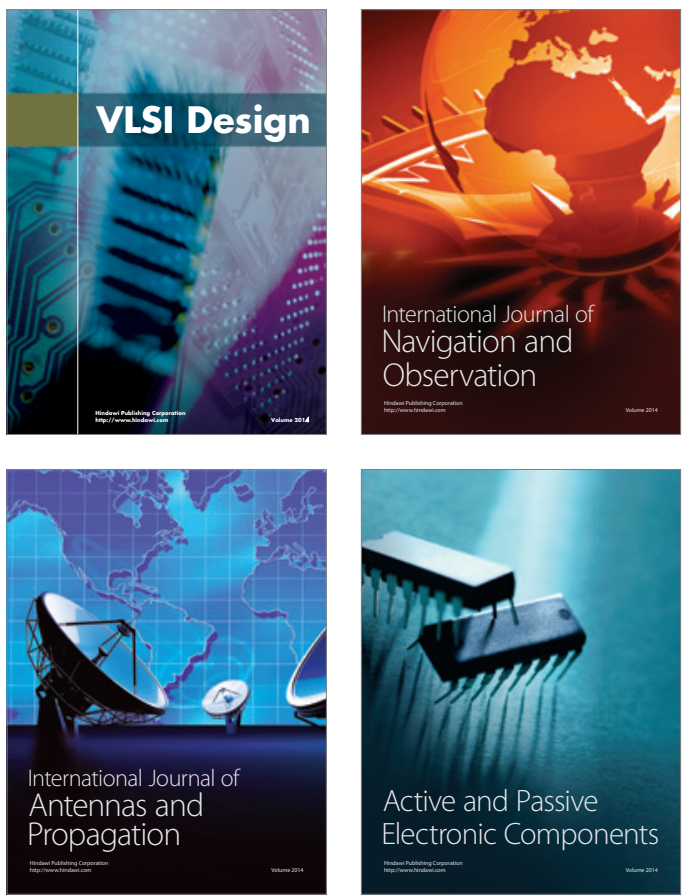
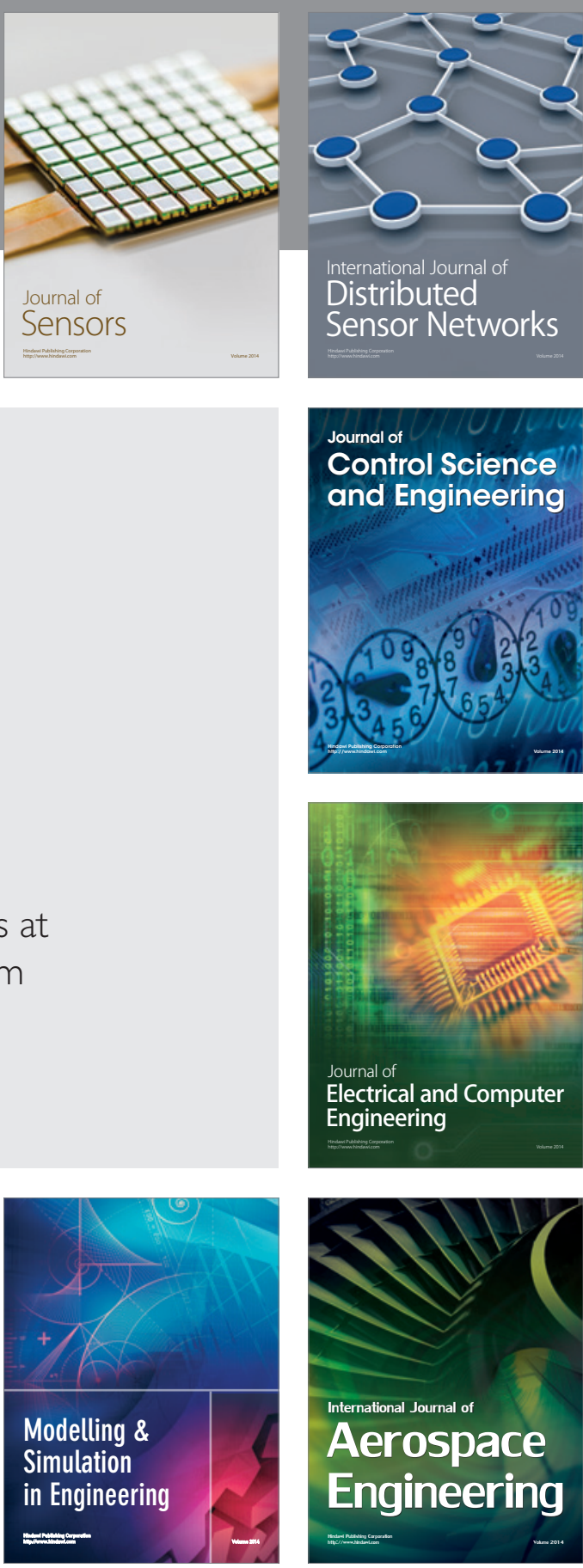

International Journal of

Distributed

Sensor Networks

Journal of

Control Science

and Engineering
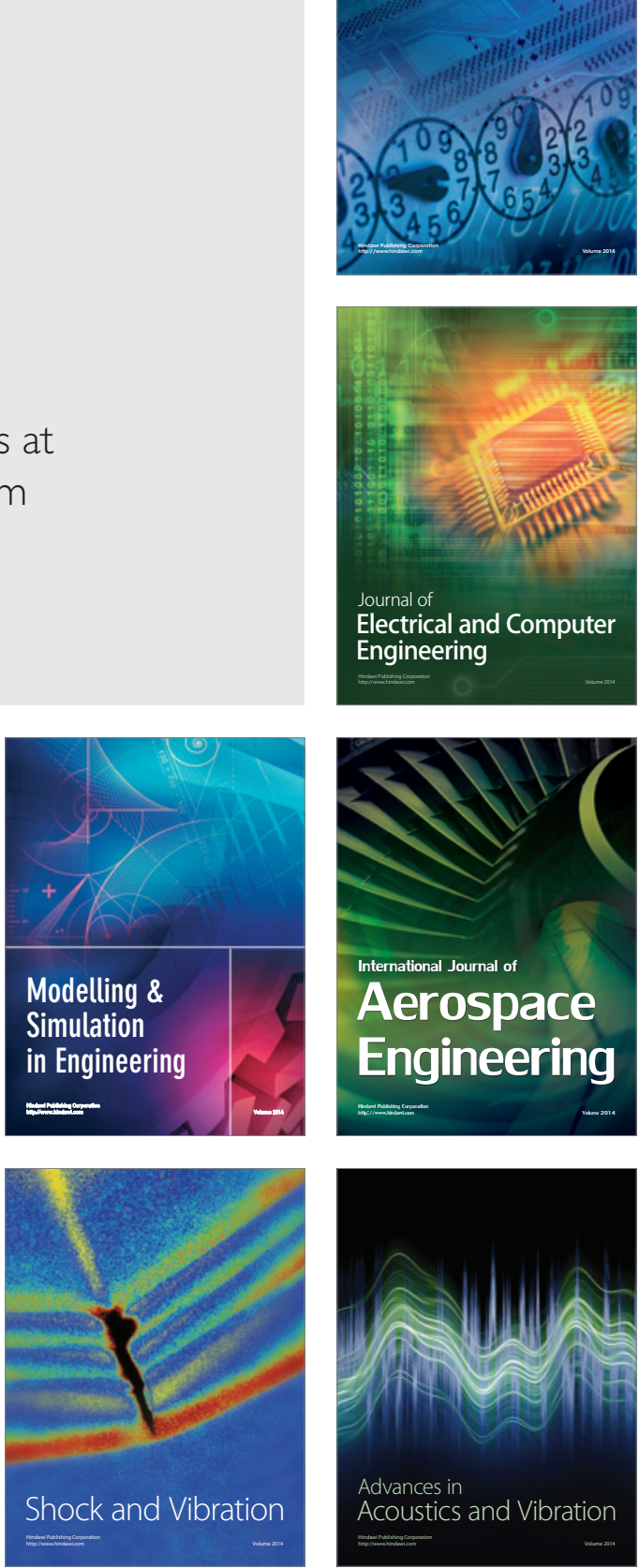